\title{
Multiple gastric carcinoids associated with parietal cell hyperplasia: intraoperative detection with a radiolabeled somatostatin analog
}

\author{
Yoshinori Hosoya ${ }^{1}$, Kitchi Satoh ${ }^{2}$, Mitsugu Hironaka ${ }^{3}$, Mitsuhiro Nokubi ${ }^{3}$, Kentaro Kurashina ${ }^{1}$, \\ Chiaki Shibayama ${ }^{4}$, Hideharu Sugimoto ${ }^{4}$, Kentaro Sugano $^{2}$, Hideo Nagai ${ }^{1}$, and Yoshikazu Yasuda ${ }^{1}$ \\ ${ }^{1}$ Department of Surgery, Jichi Medical University, 3311-1 Shimotsuke, Tochigi 329-0498, Japan \\ ${ }^{2}$ Department of Gastroenterology, Jichi Medical University, Tochigi, Japan \\ ${ }^{3}$ Department of Pathology, Jichi Medical University, Tochigi, Japan \\ ${ }^{4}$ Department of Radiology, Jichi Medical University, Tochigi, Japan
}

\begin{abstract}
We describe a 30-year-old man in whom upper endoscopy revealed multiple gastric carcinoids. The peripheral blood gastrin level was $2400 \mathrm{ng} / \mathrm{ml}$ (normal range, $<200 \mathrm{ng} / \mathrm{ml}$ ). Mucosal biopsy of the gastric body and fundus showed no atrophy; typical type $A$ chronic atrophic gastritis was thus unlikely. Neither abdominal computed tomography nor selective angiography showed any evidence of tumor in the pancreas or at its periphery. However, the possibility of microgastrinoma could not be ruled out. We performed radioguided surgery with a somatostatin analog, diethylenetriamine pentaacetic acid-D-Phe1-octreotide labeled with ${ }^{111}$ In (Octreo Scan). The location of the carcinoids was confirmed. Gastrinoma was ruled out. Total gastrectomy was performed, and the gastrin level decreased to the normal range. Macroscopically, 20 carcinoid tumors, measuring $30 \mathrm{~mm}$ in maximum diameter, were confirmed. Microscopic examination showed large numbers of endocrine cell micronests. Hyperplasia of parietal cells was observed, suggesting early-stage type A chronic atrophic gastritis. The antrum contained increased numbers of gastrin-positive cells, which probably caused the preoperative hypergastrinemia.
\end{abstract}

Key words Gastric carcinoid - Parietal cell hyperplasia • Radiolabeled somatostatin analog

\section{Introduction}

Gastric carcinoid tumors (GCTs) are classified into three types based on pathogenesis and underlying factors [1]: type I, autoimmune gastritis (AIG) with atrophy of the gastric fundic gland region and hypergastrinemia, complicated by type A chronic atrophic gastritis (CAG-A); type II, GCTs associated with multiple endocrine neoplasia (MEN)-Zollinger-Ellison syndrome; and type III, sporadic GCTs. Type I and II lesions cause hypergastrinemia, and hyperplasia of

Offprint requests to: Y. Hosoya

Received: December 25, 2007 / Accepted: March 19, 2008 enterochromaffin-like (ECL) cells may be involved in the pathogenesis of carcinoid tumors [2].

We describe a patient with gastric carcinoid tumors and hypergastrinemia who underwent radioguided surgery with the use of a somatostatin analog. Differential diagnosis suggested early-stage CAG-A with lack of acid production by hypertrophic parietal cells $[3,4]$.

The Ethics Committee of Jichi Medical University approved the peripheral blood/tumor DNA analysis (No. 01-37) and the protocol for radioguided surgery using Octreo Scan (Mallinkrodt-Tyco, Petten, Holland) (No. 03-74). Written informed consent was obtained from the patient.

\section{Case report}

The patient was a 30-year-old man. The family history was not contributory. He had previously received Helicobacter pylori eradication therapy. A routine medical checkup with upper gastrointestinal barium examination showed multiple polypoid lesions in the stomach. Endoscopy revealed pedunculated polypoid lesions, measuring $30 \mathrm{~mm}$ in the upper portion of the gastric body and $20 \mathrm{~mm}$ in the lower portion of the gastric body (Fig. 1). Biopsy suggested carcinoids. In addition, many small protruding carcinoid tumors, measuring approximately $5 \mathrm{~mm}$, were detected in the stomach. The peripheral blood level of gastrin was $2400 \mathrm{ng} / \mathrm{ml}$ (normal range, $200 \mathrm{ng} / \mathrm{ml}$ or less). Neither brain computed tomography (CT) nor cervical echography revealed any evidence of tumor. There was no loss of heterozygosity $(\mathrm{LOH})$ at the MEN1 gene in DNA collected from peripheral blood. On four-point biopsy (updated Sydney system), the patient was negative for $H$. pylori, with no mucosal atrophy. Only mild inflammation was present; these findings did not suggest typical CAG-A.

Abdominal CT showed no evidence of a pancreatic tumor. However, a microgastrinoma was considered as 

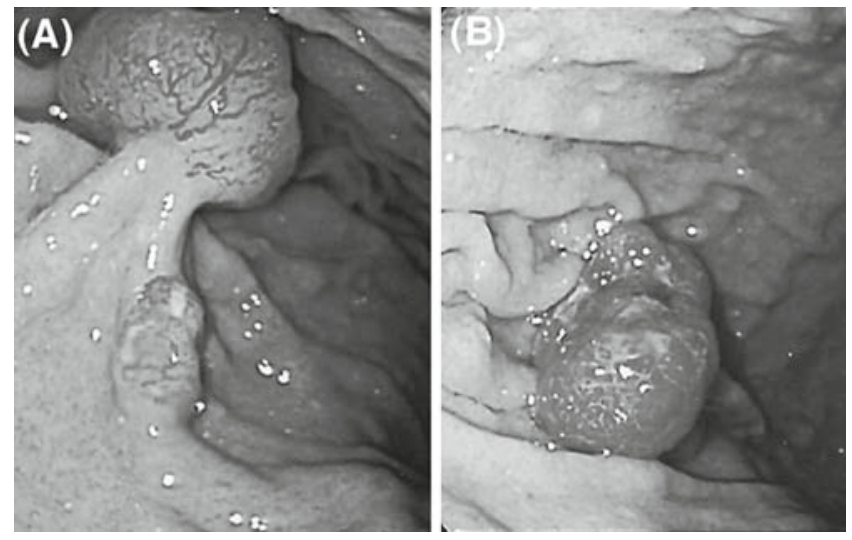

Fig. 1A,B. Gastroscopy. A A pedunculated lesion in the upper portion of the stomach. At the pedicle base, a small protrusion can be noted. B In the greater curvature of the inferior gastric body, a protrusion measuring approximately $20 \mathrm{~mm}$ can be observed. At the periphery, multiple protrusions, measuring $5 \mathrm{~mm}$ or less, are present

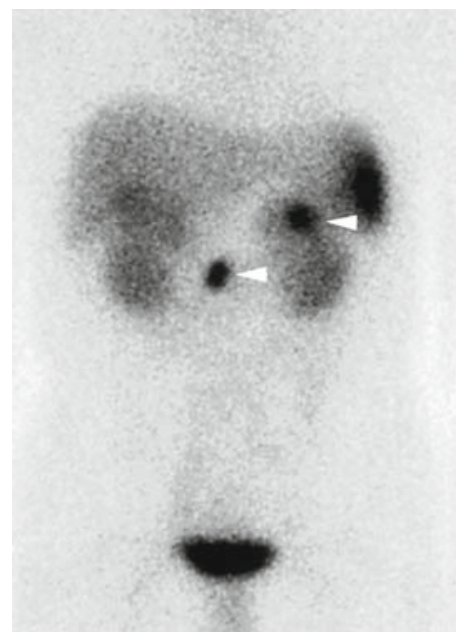

Fig. 2. Anterior view of ${ }^{111}$ In-labeled somatostatin analog (Octreo Scan; Mallinkrodt-Tyco) whole-body imaging demonstrated two areas with high uptake in the upper abdomen (arrowheads)

a potential cause of the hypergastrinemia. Selective arteriography and a calcium-loading test were performed. There were no hypervascular lesions in the pancreas or duodenum. The gastrin level was high after hepatic, perirenal, and peripancreatic arterial loading.

A test with a somatostatin analog, diethylenetriamine pentaacetic acid (DTPA)-D-Phe1-octreotide (pentetreotide), labeled with ${ }^{111}$ In (Octreo Scan; MallinkrodtTyco), showed high uptake at two points adjacent to the stomach (Fig. 2). Laparotomy was performed $20 \mathrm{~h}$ after the intravenous injection of this somatostatin analog. With the use of a hand-held NAVIGATOR GPS system (Tyco, U.S. Surgical, Norwalk, CT, USA), the energy-

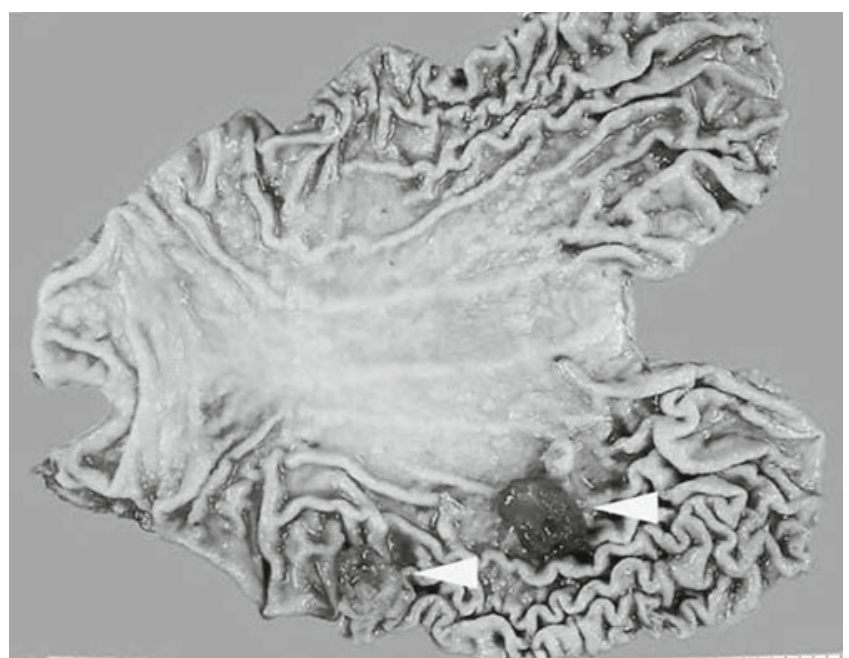

Fig. 3. Resected specimen: arrowheads show the carcinoids at the two sites of uptake of Octreo Scan (Mallinkrodt-Tyco)

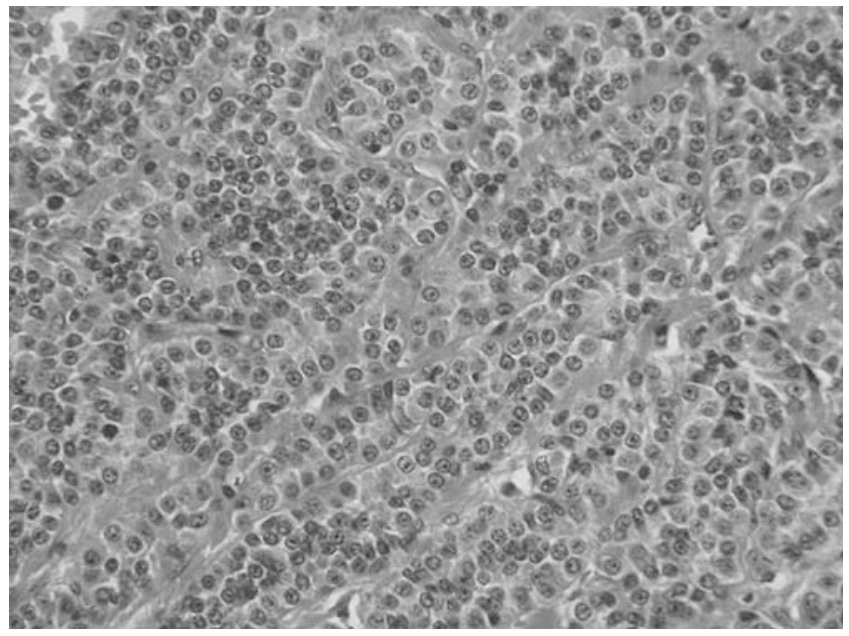

Fig. 4. Histopathological findings of the carcinoid tumor. $\mathrm{H} \& \mathrm{E}, \times 400$

distinguishing circuit was matched to ${ }^{111} \mathrm{In}$. On the Octreo Scan test, two uptake sites were present in the gastric wall, with counts ranging from 100 to 130. There were no high-count sites in the pancreas or at its periphery. Total gastrectomy with regional lymph node dissection was performed; the resected specimen is shown in Fig. 3. The extirpated specimen was photographed by a nuclear medicine procedure. We confirmed that the carcinoids at the two uptake sites had been completely extirpated.

Microscopically, the two pedunculated polyps consisted of small uniform cells that had central nuclei with no mitotic activity or necrosis. Rosette-like formations were recognized, suggesting carcinoid tumors (Fig. 4). The neoplastic cells infiltrated into the submucosa. Neither lymphatic vessel permeation nor lymph 


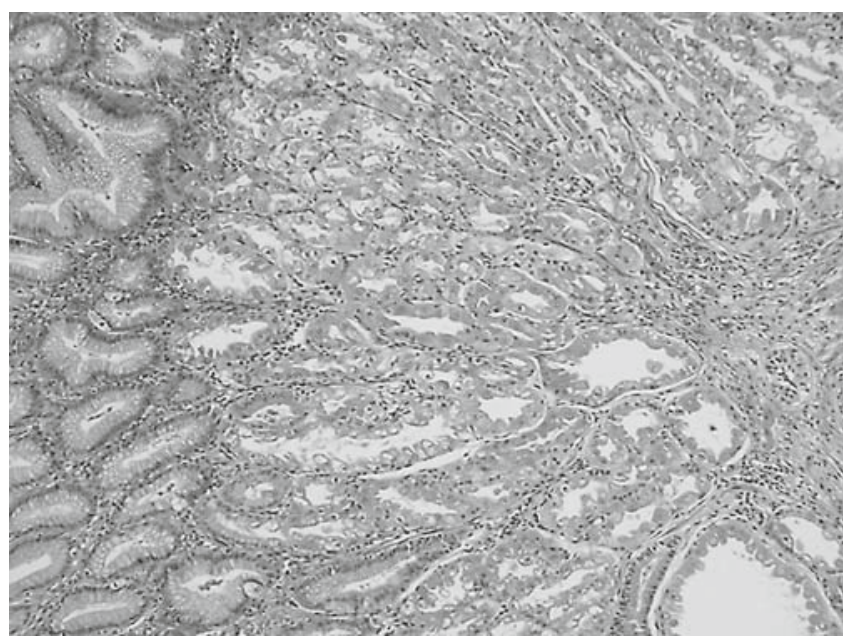

Fig. 5. Hyperplasia of parietal cells in the gastric fundic glands. $\mathrm{H} \& \mathrm{E}, \times 100$

node metastasis was detected. Small tumors diffusely scattered in the gastric mucosa were composed of endocrine-cell micronests measuring $0.5 \mathrm{~mm}$ or less. Immunohistochemically, the pedunculated polyps and micronests were diffusely positive for chromogranin A and synaptophysin, and negative for gastrin. In the antrum, neither intestinal metaplasia nor inflammatory cells were detected. Gastrin-positive cells were increased. Parietal cells in the gastric fundic glands showed hyperplasia (Fig. 5). There was no LOH at the MEN1 gene in tumor or normal gastric mucosa.

Immediately after surgery, the patient's gastrin level decreased to the normal range. There has been no tumor recurrence or hypergastrinemia during 3 years of follow-up.

\section{Discussion}

Type A chronic atrophic gastritis (CAG-A) causes marked atrophy of the gastric fundic gland and absence of acidity, leading to hypergastrinemia [5]. Gastric carcinoid tumors (GCTs) are the most frequent complication of CAG-A, occurring in $65 \%$ to $75 \%$ of cases [6]. The incidence of GCTs in patients with MEN-ZollingerEllison syndrome ranges from $5 \%$ to $10 \%$. Carcinoids may develop via hypergastrinemia and hyperplasia in ECL cells [2], as demonstrated for CAG-A. In our patient, biopsy of the gastric body showed no mucosal atrophy. Given the patient's age, we assumed that the presence of gastrinoma was involved in the pathogenesis of the GCTs, without diagnosing CAG-A. Selective angiography and a calcium-loading test were performed. However, the presence or absence of microgastrinoma could not be ascertained.
Owing to the risk of lymph node metastasis, we decided to perform regional lymph node dissection and gastrectomy to treat the carcinoids in the gastric body, which measured $30 \mathrm{~mm}$ and $20 \mathrm{~mm}$, respectively, in the upper and lower portions [7]. During surgery, we evaluated the presence or absence of gastrinoma. Many gastrinoma lesions are small, and $7 \%$ to $33 \%$ are ectopic, i.e., they are present in extrapancreatic locations [8]. Therefore, when suspected lesions are not found on CT and magnetic resonance imaging, intraoperative echography and loading tests must be performed [9].

Patients with gastrinoma have increased expression of somatostatin receptors (SSRs) [10]. Octreo Scan may be more useful than other diagnostic imaging procedures for the localization of gastrinomas and the detection of microtumors [11]. Woltering et al. [12] successfully detected an occult gastrinoma with an intraoperative gamma probe. We used Octreo Scan, an accurate and noninvasive technique, to evaluate the presence or absence of occult gastrinoma. GCTs have SSRs, and SSR scintigraphy has a high diagnostic accuracy for GCTs [13]. Rodriguez et al. [14] described Octreo Scanguided total resection of a pulmonary carcinoid tumor, done with the use of a gamma probe. Several studies have provided evidence that Octreo Scan is useful for the intraoperative diagnosis of carcinoids and microgastrinomas [12-15]. However, in the abdominal cavity, especially in the liver and around the spleen, analog uptake is high, making it difficult to differentiate tumors from normal tissue in some cases; radioguided surgery thus remains controversial [16]. In our patient, Octreo Scan uptake was detected in the pancreas and at its periphery. However, the count was not high, and uptake was uniform. Therefore, the possibility of gastrinoma could be ruled out, and we confirmed that the two sites of increased uptake were the gastric carcinoids. Typical macroscopic findings of GCTs show an elevated or submucosal tumor with a small depression of the top. The pedunculated tumors in the present patient seemed to be a rare and peculiar form.

Primary carcinoids may develop not only in the stomach and large intestine but also in the small intestine, in which detection is difficult [17]. The localization of microgastrinomas and insulinomas is often challenging. Adjusting the direction of a hand-held probe may facilitate differentiation between normal tissue and high-count areas. Probe-guided techniques using Octreo Scan may be useful for the intraoperative diagnosis of digestive hormone-producing tumors involving SSRs, such as neuroendocrine gastroenteropancreatic tumors.

Experimental studies have shown that $H$. pylori infection causes atrophy of the gastric mucosa and hypergastrinemia, leading to carcinoid formation [18]. Sato et al. [19] reported an association between $H$. pylori 
infection-related atrophy of the gastric mucosa and GCTs in Japanese patients without CAG-A. Our patient had a history of $H$. pylori infection and eradication therapy 6 months previously. Histologically, however, there was no atrophy of the gastric mucosa. Therefore, the H. pylori infection may not have had a role in the pathogenesis of the GCTs. The histopathological findings included hyperplasia of parietal cells in the gastric fundic glands, consistent with the findings of early-stage CAG-A reported by Torbenson et al. [3] and Stolte et al. [4]. Recently, Abraham et al. [20] (from the same group as Torbenson et al. [3]) described a 54-year-old patient with achlorhydria, multiple GCTs, and parietal cell hyperplasia and referred to the case as "a new disorder". Our case appears to meet the criteria for earlystage CAG-A proposed by Torbenson et al. [3] and Stolte et al.[4] and may thus also be considered "a new disorder."

\section{References}

1. Rindi G, Bordi C, Rappel S, La Rosa S, Stolte M, Solcia E. Gastric carcinoids and neuroendocrine carcinomas: pathogenesis, pathology, and behavior. World J Surg 1996;20:168-72.

2. Rindi G, Azzoni C, La Rosa S, Klersy C, Paolotti D, Rappel S, et al. ECL cell tumor and poorly differentiated endocrine carcinoma of the stomach: prognostic evaluation by pathological analysis. Gastroenterology 1999;116:532-42.

3. Torbenson M, Abraham SC, Boitnott J, Yardley JH, Wu TT. Autoimmune gastritis: distinct histological and immunohistochemical findings before complete loss of oxyntic glands. Mod Pathol 2002;15:102-9.

4. Stolte M, Baumann K, Bethke B, Ritter M, Lauer E, Eidt H. Active autoimmune gastritis without total atrophy of the glands. Z Gastroenterol 1992;30:729-35.

5. Muller J, Kirchner T, Müller-Hermelink HK. Gastric endocrine cell hyperplasia and carcinoid tumors in atrophic gastritis type A. Am J Surg Pathol 1987;11:909-17.

6. Ahlman H, Kölby L, Lundell L, Olbe L, Wängberg B, Granérus $\mathrm{G}$, et al. Clinical management of gastric carcinoid tumors. Digestion 1994;55 Suppl 3:77-85.

7. Soga J. Gastric carcinoids: a statistical evaluation of 1094 cases collected from the literature. Surg Today 1997;27:892-901.
8. Stabile BE, Morrow DJ, Passaro E Jr. The gastrinoma triangle operative implications. Am J Surg 1984;147:25-31.

9. Turner JJ, Wren AM, Jackson JE, Thakker RV, Meeran K. Localization of gastrinomas by selective intra-arterial calcium injection. Clin Endocrinol 2002;57:821-5.

10. Slooter GD, Mearadji A, Breeman WA, Marquet RL, de Jong M, Krenning EP, et al. Somatostatin receptor imaging, therapy and new strategies in patients with neuroendocrine tumors. Br J Surg 2001;88:31-40.

11. Gibril F, Reynolds JC, Doppman JL, Chen CC, Venzon DJ, Termanini B, et al. Somatostatin receptor scintigraphy: its sensitivity compared with that of other imaging methods in detecting primary and metastatic gastrinoma. Ann Intern Med 1996;125: $26-34$.

12. Woltering EA, Barrie R, O'Dorisio TM, O'Dorisio MS, Nance R, Cook DM. Detection of occult gastrinoma with 125I-labeled lanerotide and intraoperative gamma detection. Surgery 1994;116: 1139-46.

13. Gibril F, Reynolds JC, Lubensky IA, Roy PK, Peghini PL, Doppman JL, et al. Ability of somatostatin receptor scintigraphy to identify patients with gastric carcinoids: a prospective study. J Nucl Med 2000;41:1646-56.

14. Rodriguez JA, Meyers MO, Jacome TH, Failla P, Harrison LH Jr. Intraoperative detection of a bronchial carcinoid with a radiolabeled somatostatin analog. Chest 2002;121:985-8.

15. Albertario S, Forti P, Bianchi C, Morone G, Tinozzi FP, Moglia $\mathrm{P}$, et al. Radioguided surgery for gastrinoma: a case report. Tumori 2002;88:S41-43.

16. Ohrvall U, Westlin JE, Nilsson S, Wilander E, Juhlin C, Rastad $\mathrm{J}$, et al. Human biodistribution of [111In] diethylenetriaminepentaacetic acid-(DTPA)-D-[Phe1]-octreotide and peroperative detection of endocrine tumors. Cancer Res 1995;55 Suppl 23: 5794S-800S.

17. Nikou GC, Lygidakis NJ, Toubanakis C, Pavlatos S, Tseleni-Balafouta S, Giannatou E, et al. Current diagnosis and treatment of gastrointestinal carcinoids in a series of 101 patients: the significance of serum chromogranin-A, somatostatin receptor scintigraphy and somatostatin analogues. Hepatogastroenterology 2005;52:731-41.

18. Kagawa J, Honda S, Kodama M, Sato R, Murakami K, Fujioka T. Enterochromaffin-like cell tumor induced by Helicobacter pylori infection in Mongolian gerbils. Helicobacter 2002;7:3907.

19. Sato Y, Iwafuchi M, Ueki J, Yoshimura A, Mochizuki T, Motoyama H, et al. Gastric carcinoid tumors without autoimmune gastritis in Japan: a relationship with Helicobacter pylori infection. Dig Dis Sci 2002;47:579-85.

20. Abraham SC, Carney JA, Ooi A, Choti MA, Argani P. Achlorhydria, parietal cell hyperplasia, and multiple gastric carcinoids: a new disorder. Am J Surg Pathol 2005;29:969-75. 